\title{
Novos paradigmas para a paisagem contemporânea: planejamento ambiental e forma urbana na cidade amazônica
}

Lucia Capanema Alvares - Graduada em Arquitetura e Urbanismo pela Universidade Federal de Minas Gerais (1988), mestre em City and Regional Planning pela Memphis State University (1992) e doutora em Regional Planning pela University of Illinois at Urbana Champaign (1999). Professora adjunta da Universidade Federal de Minas Gerais e associada do Instituto Cidade. Endereço eletrônico: luciacapanema@terra.com.br.

Paola Lisboa Codo Dias - Graduada em Arquitetura e Urbanismo pela Universidade Federal de Minas Gerais (2008). Atualmente trabalha na TECTRAN, desenvolvendo ferramentas de planejamento metropolitano para governos estaduais (MG e ES). Endereço eletrônico: paolacodo@yahoo.com.br.

\section{Resumo}

Desde o século XIX, vários paradigmas do planejamento urbano e da paisagem têm sido substituídos por outros conceitos, todos tentando responder às demandas sociais e econômicas correntes. Tratarse-á principalmente de conceitos como a ecogênese, a ecologia da paisagem e sistemas urbanos de áreas livres. A influência desses conceitos na forma urbana e no desenho ambiental é analisada em um estudo de caso: Parauapebas, uma cidade emancipada há quase vinte anos, que possui 120.000 habitantes e é porta de entrada para a Floresta Nacional de Carajás, no sudeste do Pará, na região Amazônica. O planejamento proposto, considerando os paradigmas correntes, é apresentado como um caminho para a preservação ambiental e a melhoria da qualidade de vida.

\section{Palavras-Chave}

Planejamento ambiental. Paradigmas correntes. Ecologia da paisagem. Espaços livres urbanos. Florestas tropicais brasileiras.

\begin{abstract}
Since the 19th century, several paradigms for urban planning and landscape have been replaced by other concepts, all of them trying to respond to the current social and economical demands. This article reports a brief exposition of these paradigms and their consequences, focusing the canons of urban planning and landscape. It will principally deal with concepts such as ecogenesis, the ecology of the landscape and urban systems of free area. The influence of these concepts in the urban format and in the environmental design is analyzed in a case study: Parauapebas, an emancipated town almost twenty years ago, with 120.000 inhabitants and it is entrance door to the National Forest of Carajás, in the southeast of Pará state, in the Amazon region. The proposed planning, considering the current paradigms, is presented as a way for preserving the environment and enhancing life quality.
\end{abstract}

\section{Keywords}

Environmental planning. Current paradigms. Ecology of landscape. Free urban spaces. Brazilian tropical forests. 


\section{INTRODUÇÃO}

A trajetória do planejamento urbano e paisagístico segue diferentes tendências e modelos ou paradigmas, fundamentados em categorias e conceitos que caracterizam o pensamento de cada época. Seguindo a evolução dos paradigmas e considerando as demandas mundiais do fim do século XX e do início do século XXI, são aqui abordadas questões ligadas ao planejamento ambiental e à paisagem. Assim, a criação e a manutenção de sistemas de espaços livres urbanos - especialmente as Áreas de Preservação Permanente (APP, como designadas pela legislação federal brasileira) - e os princípios da ecologia da paisagem e da ecogênese são o foco deste artigo.

A intenção deste artigo é demonstrar como as novas realidades sociais, econômicas, ambientais, culturais e legais têm sido incorporadas aos paradigmas de planejamento urbano e da paisagem, e como tais paradigmas podem ser absorvidos por projetos e planos ambientalmente responsáveis. A evolução dos paradigmas do planejamento, bem como o estado da arte do planejamento paisagístico foram compreendidos a partir de revisão bibliográfica e pesquisa documental comparativa. O caso de Parauapebas (Pará, Brasil), apresentado como exemplo, foi investigado com base em dados primários coletados pelas autoras e em dados secundários obtidos em documentos da Prefeitura de Parauapebas, em pesquisas anteriores e na internet. Apontamos, como resultado, que o plano ambiental propõe zonas restritivas e de preservação baseadas nos paradigmas aqui discutidos. Diretrizes para o uso do solo e o desenho urbano são também recomendadas.

\section{PARADIGMAS DO PLANEJAMENTO URBANO}

Segundo Álvares (1992), os paradigmas do planejamento urbano no mundo seguem uma linha evolutiva. Sua história político-econômica pode ser sistematizada em três dimensões: temática, processual - ou político-administrativa - e ideológica. A evolução temática partiu de um planejamento das questões físico-territoriais, evoluiu para englobar um ou outro aspecto social ou econômico, até chegar a um planejamento multidisciplinar. A evolução processual partiu da repressão à participação, quando o planejamento se fazia nos gabinetes sob o comando das elites, evoluindo para um planejamento centralizado e dominado pelos tecnoburocratas que incorporavam algumas demandas da sociedade, orientandose finalmente para um planejamento participativo e descentralizado. A terceira dimensão partiu do planejamento concentrador de riquezas, que visava acumular capital nos investimentos industriais, passa por um momento neoliberal, em que o Estado adota uma estratégia de planejamento laissez-faire, já apontando para um 
planejamento inclusivo, de melhor distribuição de riquezas e de empoderamento por meio da capacitação.

No Brasil, a terceira dimensão é marcada pelas seguintes características: na fase colonial, há ausência de planejamento; na República Velha, quando se iniciou o processo de industrialização, observa-se um urbanismo pontual, pouco planejado e elitista; nos governos populistas (1930-1964), quando o país se torna urbano e industrializado, adota-se um planejamento físico-territorial, centralizado e concentrador; durante a ditadura militar e na Nova República (1964-1988), o planejamento é ainda físico-territorial, centralizado, tecnoburocrata e concentrador; finalmente, na fase pós-1988 - ano da promulgação da nova Constituição -, assiste-se à reorganização das estruturas e a processos de planejamento de forma mais descentralizada, democrática e inclusiva. Já em 2001, o Estatuto da Cidade (Lei n. ${ }^{\circ}$ 10.257) amplia o leque de instrumentos de gestão, uso e ocupação do solo centrado na gestão democrática, na participação, na descentralização, na inclusão e na redistribuição. Os planos diretores, segundo o Estatuto das Cidades, devem priorizar os espaços públicos, a mobilidade e a acessibilidade para todos.

$\mathrm{Na}$ análise oferecida por Álvares (1992), pode-se constatar que as variáveis temáticas (físico-territoriais, econômicas e sociais), político-administrativas (descentralização e participação) e ideológicas (distribuição de riquezas e inclusão social) têm sido incorporadas ao planejamento em decorrência de pressões reais. No planejamento da paisagem, e a partir dessa matriz, pode-se advogar a consideração também da dimensão formal e da dimensão ambiental a partir da década de 70 do século XX.

\section{OS PARADIGMAS FORMAIS}

Do ponto de vista da forma urbana e da paisagem, pode-se chamar a atenção para uma evolução razoavelmente contínua desde os fins da Idade Média até o Barroco (no aspecto urbanístico) e o Ecletismo (no paisagismo). Enquanto o Barroco se afiliava à exuberância estética e ao monumentalismo, o Ecletismo, de influência anglo-gaulês, filiava-se ao romantismo idílico (MACEDO, 1999). Ambos sofrerão a grande ruptura moderna: o urbanismo, ainda próximo à Europa, proporá modelos baseados na tipificação do homem e no funcionalismo ortogonal, embora no Brasil aspirasse por alguma liberdade formal; ainda no Brasil, o paisagismo aproximar-se-á das influências dos EUA, fundando uma síntese original e nacionalista.

Ambos, urbanismo e paisagismo, passarão pela ruptura pós-moderna, que significará, no urbanismo, a revalorização dos espaços públicos e sua diversidade de usos, a opção por pequenas intervenções, e um léxico mais vasto e complexo 
de intervenções; no paisagismo significará, além da cenarização, uma ampliação das possibilidades e linhas projetuais (MACEDO, 1999).

\section{OS PARADIGMAS DO PLANEJAMENTO AMBIENTAL}

A palavra "ecologia” foi forjada em 1866 por Haeckel, zoologista e biólogo alemão, e o termo "ecossistema" foi criado em 1935 pelo ecólogo britânico Tansley. Todavia, somente na virada dos anos 60-70, o planejamento ambiental toma corpo por meio dos trabalhos de Halprin (1965) e McHarg (1969). Eles propunham um planejamento que considerasse questões sistêmicas e questões ecológicas como base para os limites e os potenciais de uso do solo e apresentaram metodologias válidas até os dias de hoje (FRANCO, 1997). Questões de ordem política e econômica não deram ao assunto a relevância que veio a ter mais tarde. A partir da década de 90, a questão ambiental passa a fazer parte das grandes preocupações mundiais e das demandas da sociedade civil organizada. O clamor por formas alternativas de gestão ambiental tem tomado corpo desde a Eco-92 e ganha espaço na medida em que falha o sistema público e se multiplicam os problemas ambientais. Entre os mais importantes paradigmas do planejamento ambiental aceitos pela comunidade acadêmica na atualidade, estão aqueles que concernem à sustentabilidade, à ecologia da paisagem e aos sistemas de espaços livres urbanos. No Brasil, particularmente, considera-se também o arcabouço legal para o tratamento das áreas de preservação permanente e a ecogênese.

\section{SUSTENTATIBILIDADE}

Ao afirmar que "o princípio da sustentabilidade surge no contexto da globalização como a marca de um limite e o sinal que reorienta o processo civilizatório da humanidade", Leff (2001, p. 15) reforça a ideia de uma demanda real pela mudança de paradigma quanto à questão ambiental. Para Victorino (2003), a questão ambiental torna-se um fator determinante na reconfiguração das estruturas governamentais e das relações entre sociedade e natureza e da sociedade consigo mesma. Segundo Machado (2000), o conceito de sustentabilidade ambiental e, mais precisamente, o de desenvolvimento urbano sustentável ainda não possuem significados precisos em certas áreas do conhecimento. Dessa forma, de maneira ampla e em consonância com a Agenda 21, pode-se dizer que o planejamento urbano sustentável é a busca da justiça socioambiental mediante instrumentos aplicados nas cidades. O planejamento urbano, por intermédio de suas intervenções e ações, deve buscar conciliar aspectos antes fragmentados, para que, em conjunto e de acordo com um pensamento integrado e complexo, consiga promover uma 
cidade ambientalmente correta e socialmente justa. Avalia-se que, para atingir o paradigma da sustentabilidade ambiental no Brasil, seguindo um continuum de evolução e incorporação de novas variáveis, ainda falta alcançar uma estrutura política, econômica e social favorável.

\section{ECOLOGIA DA PAISAGEM}

A expressão “ecologia da paisagem”, criada em 1937 por Troll, significa o encontro de todas as ciências naturais, da geografia à biologia, para analisar a relação espacial entre ecossistemas e seus fragmentos. Enfatizando áreas heterogêneas, a ecologia da paisagem focaliza os fluxos de seres vivos, a alteração das estruturas com menos mobilidade e os processos ecológicos. O fator humano ganha relevância ímpar quando se considera a fragmentação, o isolamento e a conectividade permitida aos ecossistemas antes naturais (matrizes) (PELLEGRINO et al., 2006; PENTEADO; KASER, 2005). Segundo Pellegrino et al., por fragmentação, entende-se a ruptura imposta a um ecossistema espacialmente contínuo; por conectividade, compreende-se "a capacidade de uma paisagem facilitar fluxos entre os seus elementos bióticos” (PELLEGRINO et al., 2006, p. 63); isolado, por sua vez, será o fragmento desconexo que não registra troca com outros fragmentos ou com a matriz.

Como contraponto a esse processo de isolamento, há, principalmente, os corredores verdes ou greenways, cujas propriedades incluem facilitar fluxos, reduzir riscos de extinção e atuar como suplemento e refúgio para a fauna. Especificamente no meio urbano, ainda segundo Pellegrino et al. (2006), os greenways promovem a manutenção da biodiversidade, a proteção de cursos d'água e podem servir como apoio à implantação de infraestrutura e estruturas de lazer.

Penteado e Kaser (2005) atentam ainda para a necessidade de manutenção do continum dos rios (que também operam como corredores), preservando as dinâmicas fluviais, as áreas alagáveis, o regime hidrológico e a ecologia fluvial. Finalmente, os autores lembram que "é parte do sucesso de um projeto [incorporar] uso humano, cultura e identidade” (PENTEADO; KASER, 2005, p. 8).

\section{SISTEMAS DE ESPAÇOS LIVRES URBANOS ${ }^{1}$}

A discussão sobre a implantação de sistemas de espaços livres públicos é uma ação recorrente na segunda metade do século XX, tanto nos meios acadêmicos como nas áreas administrativas. Nos estudos acadêmicos, parte-se do princípio

1 Apoiamo-nos aqui nos textos, não publicados, elaborados, em 2006, pelos professores Silvio Macedo, Fabio Robba e Eugênio Queiroga para o Projeto Quapá-SEL. 
de que em toda a cidade existe um sistema de espaços livres públicos e privados, seja ele planejado ou casuístico, e de que o espaço público é um elemento urbano fundamental para o desempenho da vida social, associado à ideia de localização, acessibilidade e distribuição, no tocante a lazer ou a conservação de recursos naturais. Chama-se espaço público não apenas aquele de propriedade pública (os bens de uso comum do povo, as ruas, as praças, os parques, os imóveis do poder público, as escolas públicas, os postos de saúde, os terminais municipais, etc.), mas também todos os lugares de apropriação pública, onde se realizam ações da esfera pública.

Os espaços livres urbanos constituem um sistema complexo, dada a relação com outros sistemas urbanos que se podem justapor ao sistema de espaços livres. Formam um sistema, apresentando, sobretudo, relações de conectividade e de complementaridade. Entre seus múltiplos papéis, por vezes sobrepostos, estão a circulação urbana, a drenagem urbana, atividades do ócio, imaginário e memória urbana, o conforto ambiental, a conservação e a requalificação ambiental, e o convívio público.

\section{ÁREAS DE PRESERVAÇÃO PERMANENTE (APP)}

Segundo Mello (2005), a cidade brasileira tem uma relação dual com seus rios: por um lado, há alguma valorização dos de maior porte que são incorporados, muitas vezes de forma artificializada, à paisagem urbana; por outro lado, e mais comumente, a cidade vira suas costas para os rios, que são degradados e invadidos. A legislação brasileira criou, em 1965, em seu Código Florestal (BRASIL, 1965), a figura das APP, visando à preservação de ecossistemas ao longo dos rios (faixas entre 50 e $500 \mathrm{~m}$ ) e ao redor de corpos d'água, nascentes, topos de morros, encostas com inclinação superior a 100\%, restingas, bordas de tabuleiros e altitudes superiores a $1800 \mathrm{~m}$. Desde então, um dos grandes conflitos com a legislação tem-se dado em áreas urbanas, onde a população carente ocupa exatamente as áreas mais frágeis ambientalmente, as APP, sobretudo aquelas junto dos rios, visto que são protegidas por lei para o parcelamento regular. O Conselho Nacional do Meio Ambiente, ao considerar a situação degradada dos rios urbanos, resolveu, em 2006, que as APP podem ser ocupadas em alguns casos (tomados certos cuidados): nos casos de utilidade pública, para servir como infraestrutura e para permitir a criação de áreas verdes públicas e, nos casos de interesse social, para facilitar a regularização fundiária. Assim, a Resolução n. ${ }^{\circ}$ 369, de 28 de março de 2006 (BRASIL, 2006), veio permitir usos sustentáveis para as APP de rios urbanos, possibilitando sua valorização e apropriação pelos cidadãos. 


\section{ECOGÊNESE}

Curado (2006) identifica na ecogênese de Fernando Chacel um novo paradigma de intervenção nas paisagens urbanas baseado na utilização de espécies nativas para a reconstituição de ecossistemas em áreas urbanas de preservação ambiental. Para Chacel, "uma das grandes preocupações, sobretudo daqueles que defendem o desenvolvimento sustentável, [é] o equilíbrio entre as paisagens cultural e natural”. Daí a ecogênese ser "impregnad[a] de intenções ecológicas, de medidas compensatórias em relação aos impactos causados, cria[ndo] um ecossistema antrópico com base no ecossistema natural" ". O essencial, ainda segundo $\mathrm{Chacel}^{3}$, “é que esses ecossistemas antrópicos de substituição, embora diferentes dos ecossistemas originais, guardem, preservem e transmitam ao futuro, os valores que possuíam para que assim continuem presentes na realidade ambiental”.

\section{O CASO DE PARAUAPEBAS (PARÁ, BRASIL)}

A região onde está localizado o município de Parauapebas, conhecida pelos violentos conflitos relacionados à posse da terra e à mineração, está a aproximadamente $700 \mathrm{~km}$ da capital, Belém. O município possui área de 7.007 $\mathrm{km}^{2}$, e cerca de $80 \%$ de seu território correspondem a unidades de conservação e a reservas indígenas. As áreas urbanizadas ao longo do rio Parauapebas e do igarapé Ilha do Coco são áreas sujeitas a inundações, enquanto as ocupações nas encostas dos morro sofrem com deslizamentos de terras (PARAUAPEBAS, 2008), como ilustrado na Figura 1.

A zona urbana de Parauapebas cobre cerca de $130 \mathrm{~km}^{2}$ e formou-se a partir da conurbação de duas ocupações pioneiras, ambas resultantes do desenvolvimento das atividades de exploração mineral da Companhia Vale do Rio Doce (atual Vale). Além da zona urbana, há também o núcleo urbano de Carajás (NUC), pertencente à Vale, que corresponde a uma típica company town e está localizada dentro da Floresta Nacional de Carajás, cobrindo cerca de $6 \mathrm{~km}^{2}$ (PARAUAPEBAS, 2008). A zona urbana atrai mais e mais residentes e negócios, enquanto o NUC é atualmente apenas ocupado pelos trabalhadores da Vale (Figura 1).

2 Palestra "Ecogênese como fator de identidade da paisagem", realizada no Conselho de Economia, Sociologia e Política da Federação do Comércio do Estado de São Paulo, Sesc e Senac no dia 9 de dezembro de 1999.

3 BARBOSA, Antônio A. M. Entrevista com Fernando Chacel. Disponível em: <http://www. vitruvius.com.br/arquitextos >. Acesso em: 1. ${ }^{\circ}$ de nov. 2005. 


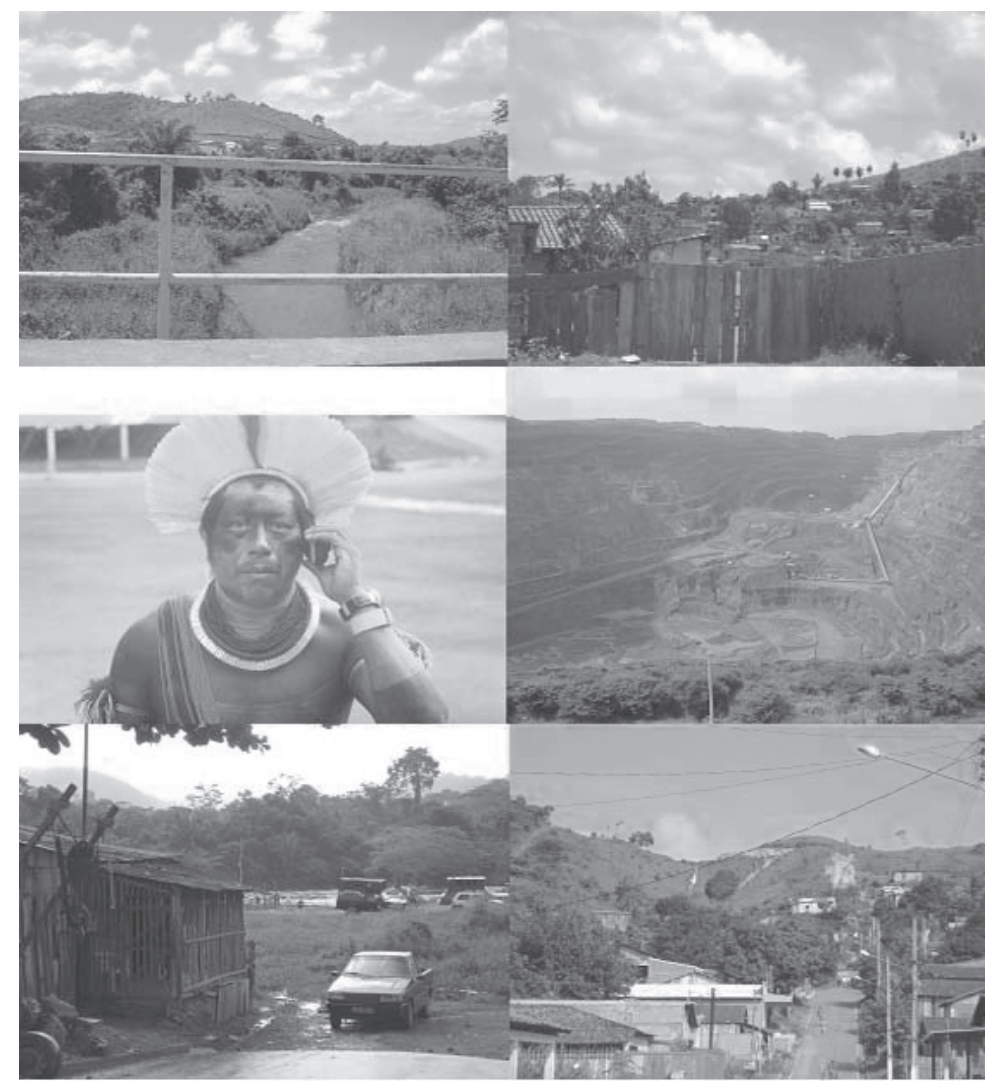

Figura 1: Situação atual de Parauapebas.

Fonte: Elaboração de Paola Lisboa Codo Dias.

Parauapebas é dotada de jazidas minerais de ferro, níquel, ouro, cobre e outros minerais valiosos; tem solo fértil e é cercada por florestas, rios, serras; possui aeroporto para aeronaves de grande porte, linha ferroviária e a rodovia estadual PA-275. Entre 1983 e 2003, a população de Parauapebas cresceu mais de $5.000 \%$, chegando a cerca de 95.000 habitantes (PREFEITURA MUNICIPAL DE PARAUAPEBAS, 2003).

No período de 2001 a 2004, a cidade cresceu 8,9\%, e sua população está estimada em mais de 120 mil habitantes. A tendência de altas taxas de crescimento para o município continua, pois a Vale tem realizado investimentos que deverão continuar atraindo investidores e moradores para a região ${ }^{4}$.

4 De acordo com a Diagonal Urbana Consultoria (2006), o emprego deve passar de 202 mil em 2004 para 626 mil em 2010 (taxa de crescimento de 20,78\%) (PARÁ NEGÓCIOS, 2008). 


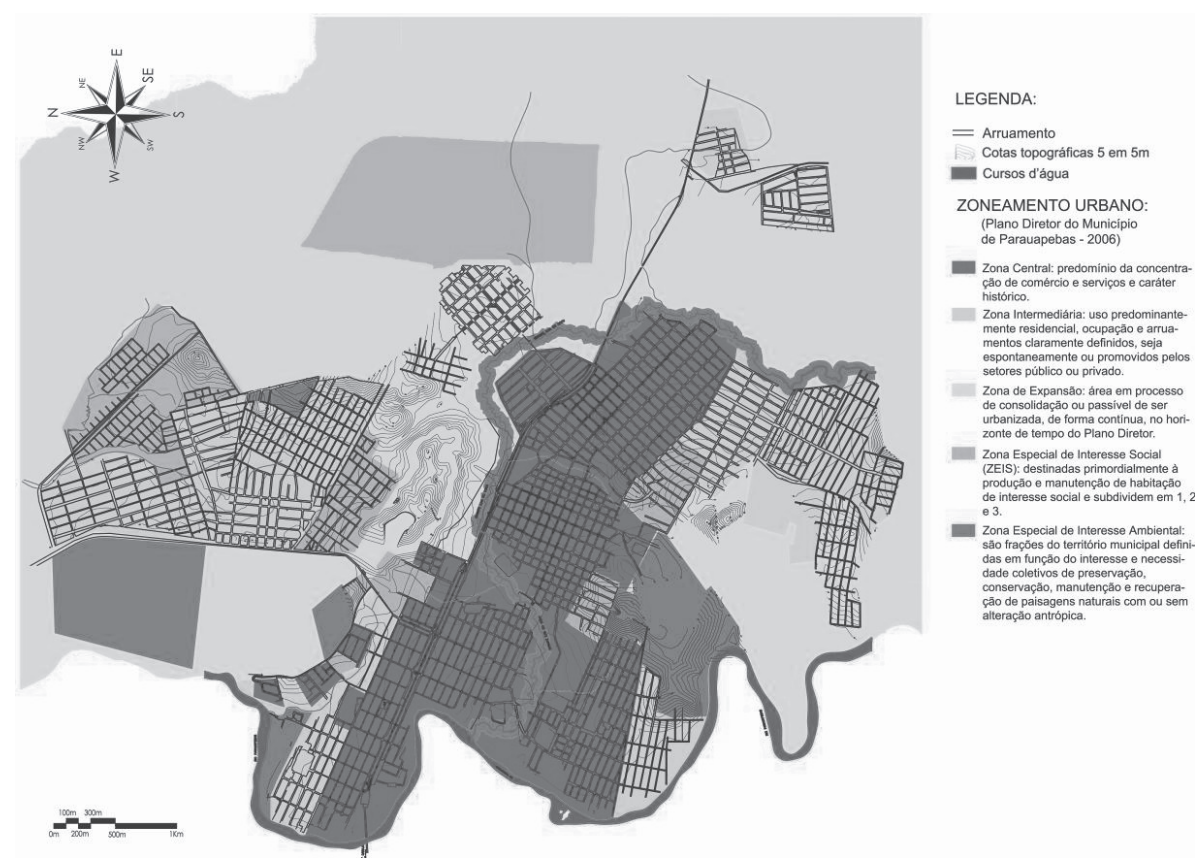

Figura 2: Mapa de zoneamento do Plano Diretor da zona urbana de Parauapebas.

Fonte: Elaborado pelas autoras com base no Plano Diretor Municipal de Parauapebas.

Em 2006, a Prefeitura aprova o Plano Diretor da cidade (Lei Municipal n. ${ }^{\circ}$ 4.328/06), criando três áreas principais dentro da zona urbana: central, intermediária e de expansão. São criadas ainda três zonas especiais que exigem tratamento especial na definição de parâmetros reguladores de usos e ocupação do solo, sobrepondo-se ao zoneamento principal: Zonas Especiais de Interesse Social (ZEIS), destinadas primordialmente à produção e à manutenção de habitação de interesse social; Zonas Especiais de Interesse Ambiental (ZEIA), definidas em função do interesse e da necessidade de preservação, conservação, manutenção e recuperação de paisagens naturais com ou sem alteração antrópica; Zonas Especiais de Segurança Alimentar (ZESA) (Figura 2).

\section{O PLANO AMBIENTAL}

O Plano Diretor de Parauapebas tem caráter genérico e não se pauta pelos novos paradigmas do planejamento ambiental, apontando para a necessidade de estudos mais aprofundados e proposições mais específicas. Entre os principais problemas ambientais da zona urbana, está a ocupação das áreas de APP, especialmente em áreas sujeitas a inundação e encostas. Sua principal potencialidade está exatamente nos fragmentos verdes e no entorno natural, enquanto o maior 
desafio para implementar as ações de conservação e desenvolvimento reside na necessidade de criar infraestruturas e estruturas urbanas. Com o intuito de mitigar problemas e maximizar benefícios, o plano aqui apresentado considera e prioriza:

a) o contexto de surgimento do município e a tendência de crescimento populacional;

b) os problemas morfológicos e ambientais específicos decorrentes da ocupação do território;

c) a qualidade de vida dos habitantes de Parauapebas;

d) a classificação das áreas de recuperação, a conservação e a intervenção ambientais de acordo com usos permitidos;

e) a adoção dos princípios da ecologia da paisagem e da ecogênese;

f) a criação de sistemas de espaços livres urbanos;

g) o respeito à legislação, em especial no que diz respeito às Áreas de Preservação Permanente (APP).

Segundo tais princípios, o Plano Diretor de Parauapebas propõe em primeiro lugar ${ }^{5}$ :

a) áreas de recuperação: retorno, dentro das possibilidades ambientais, da paisagem original, com possível supressão de elementos antrópicos e introdução de elementos naturais;

b) áreas de conservação: proteção da paisagem existente com a permanência dos elementos antrópicos e naturais;

c) áreas de intervenção: reinvenção da paisagem por meio da utilização dos elementos antrópicos e naturais.

Superpondo-se às áreas mencionadas, propõe-se que, na recomposição dos ambientes urbanizados com a utilização de elementos nativos, sejam adotados os modelos da Ecogênese (MELLO, 2005):

a) modelo fechado: áreas onde a visibilidade e os acessos são dificultados, pois são de máxima conservação ou recuperação;

b) modelo semiaberto: áreas onde a visibilidade e os deslocamentos são controlados, pois são áreas de conservação ou de intervenção controlada;

c) modelo aberto: áreas de transição da paisagem, onde o passeio e o convívio são incentivados, pois trata-se de áreas de intervenção destinadas ao lazer e aos uso sustentável.

5 Segundo metodologia sugerida por Maciel (1998). 
Dessa forma, considerando tanto os princípios quanto os modelos supracitados, propõe-se, por fim, a criação de um sistema de espaços livres na zona urbana, de forma a obedecer aos cânones da Ecologia da Paisagem:

a) conectar fragmentos às matrizes urbanas e rurais - de extrema importância no caso das florestas e reservas de Parauapebas;

b) criar corredores verdes que acomodem a infraestrutura urbana e de lazer, aumentando a acessibilidade e a mobilidade, com usos e ocupações devidamente limitados por lei;

c) criar parques lineares em corredores ou em APP, que incentivem a apropriação sustentável das áreas verdes urbanas pelos cidadãos, tornando-os, acima de tudo, espaços de vida pública.

Traduzindo a superposição de todos esses aspectos, o plano propõe o seguinte (ver figuras 3 e 4):

a) criação de um parque linear ao longo do igarapé Ilha do Coco, que integre as Áreas de Preservação Permanente, principalmente às margens dos cursos d'água e nas encostas da cidade;

b) criação de infraestrutura verde nos terrenos livres e residuais do tecido urbano, aproveitando as Áreas de Preservação Permanente (Código Florestal) e as Zonas Especiais de Interesse Ambiental (PD);

c) qualificação dessas áreas livres, aliando a necessidade de preservação biológica e física às necessidades das diferentes camadas da população (áreas de lazer e convívio público);

d) definição de parâmetros restritivos ao uso e à ocupação do solo em toda a zona urbana segundo as especificidades locais;

e) desenho urbano que favoreça o respeito aos princípios e modelos de planejamento, às restrições legais e à valorização das identidades locais;

f) criação de um "sentimento de pertencimento" coletivo, evitando ocupações irregulares em áreas impróprias e gerando uma proteção mais efetiva das APP e Zonas de Interesse Ambiental (MELLO, 2005). 


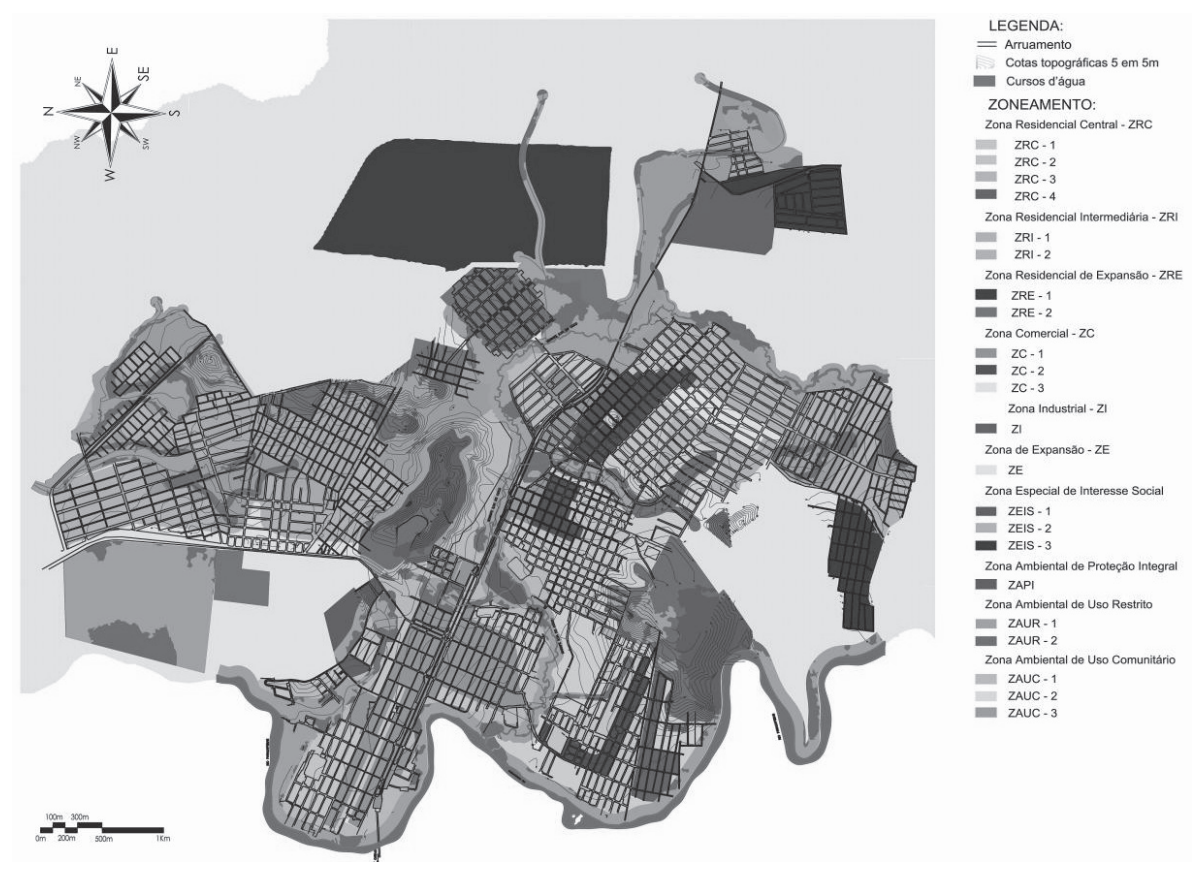

Figura 3: Mapa de diretrizes de intervenção urbana.

Fonte: Elaboração das autoras.

\section{ZONEAMENTO AMBIENTAL}

Considerando os aspectos históricos, populacionais, econômicos, de infraestrutura, de posse da terra e ambientais, o plano divide a zona urbana em 24 zonas, detalhando a classificação proposta no zoneamento do Plano Diretor (ver Tabela 1). 
Tabela 1 - Zoneamento ambiental.

\begin{tabular}{|c|c|c|c|c|c|c|}
\hline \multirow[b]{2}{*}{ Zonas } & \multicolumn{6}{|c|}{ Características } \\
\hline & História & $\begin{array}{l}\text { Crescimento } \\
\text { Populacional }\end{array}$ & $\begin{array}{c}\text { Atividades } \\
\text { Econômicas }\end{array}$ & $\begin{array}{c}\text { Problemas } \\
\text { Infra-estrutura }\end{array}$ & $\begin{array}{c}\text { Posse da } \\
\text { Terra }\end{array}$ & $\begin{array}{l}\text { Problemas } \\
\text { Ambientais }\end{array}$ \\
\hline \multicolumn{7}{|l|}{ Residencial } \\
\hline \multicolumn{7}{|l|}{$\mathrm{ZRC1}$} \\
\hline \multicolumn{7}{|l|}{ ZRC2 } \\
\hline \multicolumn{7}{|l|}{ ZRC3 } \\
\hline \multicolumn{7}{|l|}{ ZRC4 } \\
\hline \multicolumn{7}{|l|}{ ZRI1 } \\
\hline \multicolumn{7}{|l|}{ ZRI2 } \\
\hline \multicolumn{7}{|l|}{ ZRE1 } \\
\hline \multicolumn{7}{|l|}{ ZRE2 } \\
\hline \multicolumn{7}{|l|}{ Comercial } \\
\hline \multicolumn{7}{|l|}{$\mathrm{ZC} 1$} \\
\hline \multicolumn{7}{|l|}{$\mathrm{ZC} 2$} \\
\hline \multicolumn{7}{|l|}{ ZC3 } \\
\hline \multicolumn{7}{|l|}{ Industrial } \\
\hline \multicolumn{7}{|l|}{ ZI } \\
\hline \multicolumn{7}{|l|}{ Expansão } \\
\hline \multicolumn{7}{|l|}{$\mathrm{ZE}$} \\
\hline \multicolumn{7}{|l|}{ Social } \\
\hline \multicolumn{7}{|l|}{ ZEIS1 } \\
\hline \multicolumn{7}{|l|}{ ZEIS2 } \\
\hline \multicolumn{7}{|l|}{ ZEIS3 } \\
\hline \multicolumn{7}{|l|}{ Ambiental } \\
\hline \multicolumn{7}{|l|}{ ZAPI } \\
\hline ZAUR1 & & & & & & \\
\hline ZAUR2 & & & & & & \\
\hline ZAUC1 & & & & & & \\
\hline ZAUC2 & & & & & & \\
\hline ZAUC3 & & & & & & \\
\hline $\mathrm{ZRC}=\mathrm{Zona}$ & idencial $\mathrm{Ce}$ & & & & & \\
\hline $\mathrm{ZRI}=\mathrm{Zona}$ & idencial Int & nediária & & & & \\
\hline $\mathrm{ZRE}=\mathrm{Zona}$ & idencial de & xpansão & & & & \\
\hline $\mathrm{ZC}=\mathrm{Zona}$ & ercial & & & & & \\
\hline $\mathrm{ZI}=\mathrm{Zona} \mathrm{Ir}$ & trial & & & & & \\
\hline $\mathrm{ZE}=\mathrm{Zona}$ & kpansão & & & & & \\
\hline ZEIS $=$ Zon & oecial de In & resse Social $(1=$ & onjuntos habita & nais $2=$ ocupação & regular) & \\
\hline ZEIA $=$ Zon & pecial de In & resse Ambiental & & & & \\
\hline $\mathrm{ZAPI}=\mathrm{Zon}$ & nbiental de & eservação Integ & & & & \\
\hline ZAUR $1=\mathrm{Z}$ & Ambiental & Uso Restrito 1 & & & & \\
\hline ZAUR2 $=\mathrm{Z}$ & Ambiental & Uso Restrito 2 & & & & \\
\hline $\mathrm{ZAUC}=\mathrm{Zo}$ & mbiental d & Comunitári & & & & \\
\hline
\end{tabular}

Fonte: Elaboração das autoras.

Cada coluna com as características das zonas aponta para um grau de uso e ocupação do solo e diretrizes gerais para a política ambiental. As diretrizes da ZAUC 3, por exemplo, são "preservar/conservar áreas verdes, reintroduzindo elementos naturais, se necessário". A criação de parques urbanos, de acordo com a Resolução n. ${ }^{\circ}$ 369/2006 (sobre APP), deve considerar os elementos naturais e culturais e as características da população do entorno com a finalidade de promover as facilidades e atividades de lazer necessárias. $\mathrm{O}$ desenho urbano deve promover a integração de usos consolidados e a preservação das áreas. A Figura 4 mostra as diretrizes gerais de desenho urbano. 

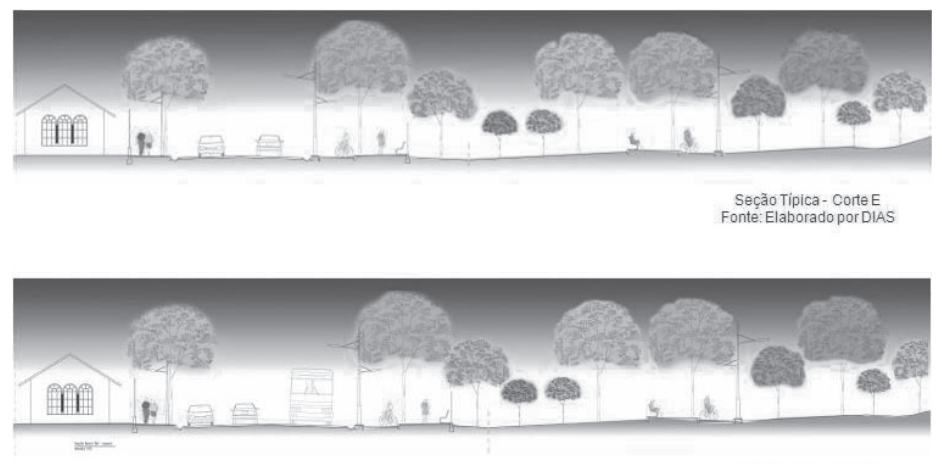

Seção Típica-CorteF
Fonte:Elaborado porDIAS
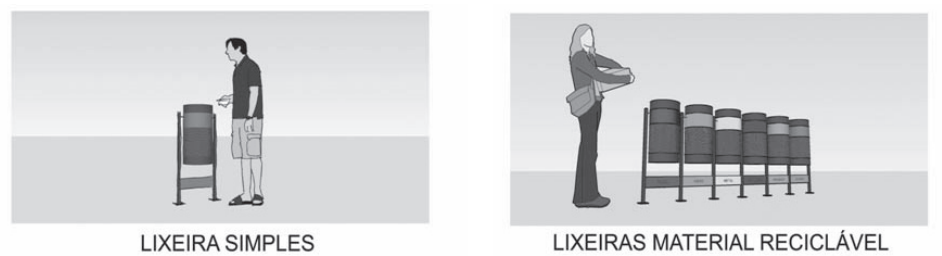

LIXEIRA SIMPLES
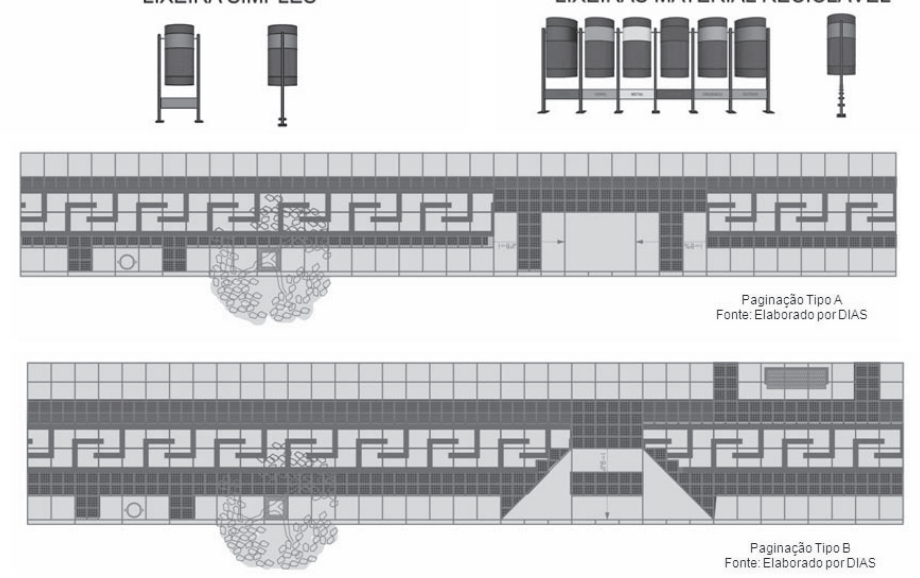

Figura 4: Diretrizes de desenho urbano.

Fonte: Elaboração das autoras com base no Plano Diretor Municipal de Parauapebas.

\section{REFERÊNCIAS}

ÁLVARES, Lúcia Capanema. Brazilian metropolises: a planning challenge. 1992. 69 f. Dissertação (Mestrado em Planejamento Urbano e Regional) - Memphis State University, Memphis, 1992.

BRASIL. Lei n. ${ }^{\circ}$ 4771, de 15 de setembro de 1965. Institui o Código Florestal. Diário Oficial da União, Brasília, DF, 16 set. 1965. Seção 1, p. 9529. 
BRASIL. Ministério do Meio Ambiente. Conselho Nacional do Meio Ambiente. Resolução n. ${ }^{\circ}$ 369. Dispõe sobre os casos excepcionais, de utilidade pública, interesse social ou baixo impacto ambiental, que possibilitam a intervenção ou a supressão de vegetação em Área de Preservação Permanente. Diário Oficial da União, Brasília, DF, 28 mar. 2006. Seção 1, p. 150-151.

CURADO, Mirian M. de C. Paisagismo contemporâneo: Fernando Chacel e o conceito de ecogênese. 2006. Dissertação (Mestrado em Urbanismo) - Faculdade de Arquitetura e Urbanismo, Universidade Federal do Rio de Janeiro, 2006.

FRANCO, Maria de Assunção R. Desenho ambiental: uma introdução à arquitetura da paisagem com o paradigma ecológico. São Paulo: Annablume, 1997.

LEFF, Enrique. Saber ambiental: sustentabilidade, racionalidade, complexidade, poder. Petropólis: Vozes, 2001.

MACEDO, Silvio S. Quadro do paisagismo no Brasil. São Paulo: EDUSP, 1999.

MACHADO, Maria Helena Ferreira. Urbanização e sustentabilidade ambiental: questões do território. Revista Brasileira de Estudos Urbanos e Regionais, Recife, ano 1, v. 3, n. 2, p. 81-95, 2000.

MACIEL, Marieta C. O projeto em arquitetura paisagística: parques e praças públicas em Belo Horizonte. São Paulo: FAU-USP, 1998.

MELLO, Sandra S. Gestão ambiental urbana dos espaços de margens dos cursos d'água. In: SEMINÁRIO NACIONAL SOBRE REGENERAÇÃO AMBIENTAL DE CIDADES: ÁGUAS URBANAS, 1., 2005, Rio de Janeiro. Anais... Rio de Janeiro: UFRJ, 2005. 1 CD-ROM.

PARAUAPEBAS. Disponível em: < http://pt.wikipedia.org/wiki/Parauapebas>. Acesso em: 9 mar. 2008.

PELLEGRINO, Paulo R. M. et al. A paisagem de borda: uma estratégia para a condução da biodiversidade e das pessoas. In: COSTA, Lucia M. S. A. (Org.). Rios e paisagem urbana em cidades brasileiras. Rio de Janeiro: Viana \& Mosley, 2006. p. 57-76.

PENTEADO, H. M.; CASER, K C . Ecologia da paisagem em projetos de orlas fluviais urbanas. In: SEMINÁRIO NACIONAL SOBRE REGENERAÇÃO AMBIENTAL DE CIDADES: ÁGUAS URBANAS, 1., 2005, Rio de Janeiro. Anais... Rio de Janeiro: UFRJ, 2005. 1 CD-ROM. 
PREFEITURA MUNICIPAL DE PARAUAPEBAS. Educação: o rumo que Parauapebas definiu e usa diariamente para crescer de verdade. 15 anos. Parauapebas, 2003. Folheto.

. Lei Municipal n. ${ }^{\circ}$ 4.328/06. Dispõe sobre o Plano Diretor do município de Parauapebas. 2006.

VICTORINO, Valério I. P. Monopólio, conflito e participação na gestão dos recursos hídricos. Ambiente \& Sociedade, Campinas, v. 6, n. 2, p.47-62, jul./dez. 2003. 